\title{
EDITORIAL
}

\section{Increasing awareness of sepsis: World Sepsis Day}

Jean-Louis Vincent*

The first ever World Sepsis Day (WSD), a great opportunity to increase awareness about sepsis, is going to be held on Sept. 13. We already have World Diabetes Day, Breast Cancer Awareness Day, World Asthma Day, World AIDS day, even a Rare Disease Day, so why not a day dedicated especially to sepsis? After all, sepsis is estimated to affect at least 18 million individuals worldwide, and with mortality rates of $25 \%$ to $30 \%$ [1,2], severe sepsis kills more individuals annually than prostate cancer, breast cancer, and HIV/AIDS combined, and the numbers of cases are increasing every year. Yet it is a condition that is poorly understood by those outside of medicine. Almost $90 \%$ of the public have never even heard of sepsis, and of those who have, less than $60 \%$ realize it is a leading cause of death [3]. But if the condition is diagnosed early and managed appropriately, lives can be saved.

So why is so little known about sepsis? Why is public awareness of other diseases so much greater than the awareness of sepsis. One key factor is that people suffering from asthma or AIDS or even cancer live with their disease from day to day, often long-term, and have the opportunity and time to speak out and to lobby politicians and others involved in health-care management for better facilities, treatments, research funding, and so on. Individuals with sepsis, in contrast, are critically ill in the intensive care unit (ICU) and unable to speak for themselves. The $50 \%$ to $60 \%$ of patients who survive could, of course, speak up when they have recovered, but these patients are often so happy to have survived that they want to move on and not look back. Alternatively, they may be unable to remember much of what happened during their ICU stay or they may suffer from ICU-related post-traumatic stress disorder [4] or depression [5], making it difficult for them to speak out. Patients with sepsis may also focus more on the primary disease process that caused their sepsis (for example, an underlying cancer, a pneumonia, or an episode of decompensated heart failure). They may even blame the hospital because their sepsis was hospital-acquired and

*Correspondence: jlvincen@ulb.ac.be

Department of Intensive Care, Erasme Hospital, Université Libre de Bruxelles, Route de Lennik 808, B-1070 Brussels, Belgium caused by a multiresistant microorganism. Patients (and their families) often do not realize that it is the fact that they were already ill with an impaired immune status and required multiple invasive procedures that increased their risk of developing a nosocomial infection rather than the hospital or staff being at fault. Interestingly, the little support that sepsis does get tends to come from relatives of patients who die from sepsis, perhaps because they realize that we did our best for their loved one, but our best was not good enough, so it is important that treatments be improved or new therapies developed.

Another key factor in the lack of public awareness of sepsis relates to the fact that there is still a lot of ambiguity about what sepsis actually is. Diabetes, breast cancer, and arthritis are all clear-cut conditions that everyone recognizes, but sepsis can be a vague term, indicative of infection, blood poisoning, septicemia, etc. If you ask intensivists what they mean by sepsis, they will generally say it is an infection with hypotension or encephalopthy or renal failure - that is, an infection with some degree of associated organ failure, not an easy concept for laypersons or even some physicians to understand. The confusion related to sepsis definitions and terminology was amplified some 20 years ago when participants at a North American consensus conference [6] confused signs of infection, such as fever and altered white blood cell count, with signs of sepsis, so that sepsis became severe sepsis, and so on and so forth. But that debate is now part of history and we must move on. Mortality rates from sepsis are too high, and new therapeutic strategies are urgently needed. The sad story of activated protein $C$ has brought us right back to square one in terms of specific anti-sepsis medication, and now we face a huge challenge in trying to convince the industry that the development of new agents is worthwhile - and financially viable!

Society as a whole needs to recognize that sepsis is a major problem in terms of mortality, morbidity, and health-care costs. We need to lobby for better treatments so that the resources will be made available and directed toward projects that ultimately will benefit patients with sepsis. The WSD is just a start to increase global awareness of this problem. There are a number of different ways to actively support the campaign - all the information and details of press conferences, open 
houses, and charity events can be found on the WSD website [7]. Let us all work together to support the WSD and to create a new focus for our efforts to improve outcomes in sepsis. Most importantly, though, this must not be just a one-day event to be filed away on Sept. 14 and forgotten about until September 2013. The impetus of this special occasion must continue throughout the year as we aim for progress.

Abbreviations

ICU, intensive care unit; WSD, World Sepsis Day.

\section{Competing interests}

The author declares that he has no competing interests.

Published: 13 September 2012

\section{References}

1. Kumar G, Kumar N, Taneja A, Kaleekal T, Tarima S, McGinley E, Jimenez E, Mohan A, Khan RA, Whittle J, Jacobs E, Nanchal R: Nationwide trends of severe sepsis in the twenty first century (2000-2007). Chest 2011, 140:1223-1231.
2. Hall MJ, Williams SJ, DeFrances CJ, Golosinsky A: Inpatient care for septicemia or sepsis: a challenge for patients and hospitals [http://www.cdc.gov/nchs/data/databriefs/db62.pdf].

3. Rubulotta FM, Ramsay G, Parker MM, Dellinger RP, Levy MM, Poeze M: An international survey: public awareness and perception of sepsis. Crit Care Med 2009, 37:167-170.

4. Davydow DS, Gifford JM, Desai SV, Needham DM, Bienvenu OJ: Posttraumatic stress disorder in general intensive care unit survivors: a systematic review. Gen Hosp Psychiatry 2008, 30:421-434.

5. Davydow DS, Gifford JM, Desai SV, Bienvenu OJ, Needham DM: Depression in general intensive care unit survivors: a systematic review. Intensive Care Med 2009, 35:796-809.

6. American College of Chest Physicians-Society of Critical Care Medicine Consensus Conference: definitions for sepsis and organ failure and guidelines for the use of innovative therapies in sepsis. Crit Care Med 1992, 20:864-874.

7. World Sepsis Day homepage [www.world-sepsis-day.org].

doi:10.1186/cc11511

Cite this article as: Vincent $\mathrm{J}$ : Increasing awareness of sepsis: World Sepsis Day. Critical Care 2012, 16:152. 